\title{
As vivências e percepções dos actores na formação inicial de professores: a figura do supervisor cooperante
}

\author{
Susana Caires \& Maria Alfredo Moreira \\ Universidade do Minho, Portugal \\ Carla Hiolanda Esteves \\ Escola Secundária de Felgueiras, Portugal \\ Diana A. Vieira \\ Instituto Politécnico do Porto, Portugal
}

\begin{abstract}
Resumo
O presente trabalho surge centrado nas vivências dos supervisores cooperantes relativamente ao processo de acompanhamento dos estágios pedagógicos. Neste, dá-se a conhecer um estudo envolvendo 155 supervisores que, ao longo do ano lectivo de 2007/8, colaboraram com quatro universidades públicas portuguesas e cuja experiência foi avaliada através do Inventário de Vivências e Percepções do Supervisor (IVPS - Esteves, Caires \& Moreira, 2008). O instrumento, composto por 77 itens, avalia três domínios centrais da vivência dos supervisores da escola: i) benefícios, ii) impacto pessoal e iii) dificuldades na adaptação às tarefas de supervisão. É nosso objectivo averiguar em que medida as variáveis "Área científica", "Anos de serviço", "Tempo de supervisão" e "Formação específica em supervisão" diferenciam as vivências e percepções dos participantes. Os dados apontam para a ausência de impacto das três primeiras variáveis referidas e para a influência da última nas vivências e percepções dos supervisores cooperantes.
\end{abstract}

Palavras-chave

Vivências; Percepções; Supervisor cooperante

\section{Introdução}

Há um reconhecimento amplo e consensual relativamente ao papel que os formadores de professores em formação inicial exercem na 
determinação da qualidade da mesma. De entre estes actores, salienta-se a figura do supervisor cooperante, também apelidado de orientador cooperante, professor do ensino não superior que exerce funções de supervisão na formação inicial de professores, enquanto elemento facilitador da promoção dos processos de socialização numa cultura profissional e consequente construção da identidade profissional - que ocorrem, privilegiadamente, em contextos de iniciação à prática pedagógica (Alarcão, 1996a; Alarcão \& Tavares, 2003; Caires, 2003; Flores, 2006; Moreira, 2005; Ribeiro, 1996, 2006; Rodrigues \& Esteves, 2003; Sá-Chaves, 2002; Vieira, 1993; Vieira, Moreira, Barbosa, Paiva \& Fernandes, 2006). São muitos e diversos os estudos que investigam a função que estes sujeitos desempenham nos processos de desenvolvimento profissional, e que, mais recentemente, se têm centrado na exploração do seu papel, discurso, ou na relação estabelecida com o supervisor da instituição do Ensino Superior (Abrantes, 2005; Albuquerque, Graça \& Januário, 2005; Barbosa, 2003; Beck \& Kosnik, 2000; Crasborn, Hennisen, Brouwer, Korthagen \& Bergen, 2008; Feiman-Nemser, 2001; Guimarães, 2005; Moreira, 2005; Parker-Katz \& Bay, 2008) e/ou com os estagiários (Galvão, 1996; Schmidt, 2008).

Reconhece-se, no panorama nacional, a ausência generalizada de formação específica para o exercício da função supervisiva (Branquinho, 2004; Estrela, Esteves \& Rodrigues, 2002; Leal, 2001; Rodrigues \& Esteves, 2003), não obstante o investimento que as instituições de Ensino Superior têm vindo a fazer nesta formação. Tal ausência pode ser explicada, em grande parte, pelo estatuto menor que a prática pedagógica tem assumido no projecto de formação inicial de professores (Alarcão, 1996b), aliado ao crescente panorama de desemprego que se vive actualmente em Portugal na classe docente. Alguns estudos têm sido, contudo, realizados, focando-se na análise das competências do supervisor e das estratégias supervisivas estimuladoras da reflexividade e da promoção de competências profissionais (Bennett, 1997; Moreira, 2005; Pajak, 1990; Parker-Katz \& Bay, 2008; Ribeiro, 2006; Riordan, 1995). Porém, raros são os que exploram as características pessoais e profissionais destes formadores, as suas motivações para a prática supervisiva, as vivências daí decorrentes ou os motivos dissuasores dessa prática. Atendendo à necessidade de identificar os motivos que poderão mobilizar estes actores para os projectos de formação inicial de professores, crê-se da maior premência a realização de trabalhos sobre o modo como percepcionam e vivenciam esta actividade. 
Os estudos desenvolvidos até à data evidenciam as percepções globalmente positivas dos supervisores cooperantes relativamente aos ganhos decorrentes da sua experiência supervisiva. Entre estas, destacam-se os ganhos na relação com os estagiários, na colaboração estabelecida com a instituição de Ensino Superior e seus docentes/supervisores, bem como na própria escola (Esteves, 2006, 2007; Esteves, Caires \& Moreira, , 2007; King, 2004; Pacheco, 1995; Parker-Katz \& Bay, 2008). Tais ganhos reportam-se não só ao nível da qualidade das interacções e "trocas" estabelecidas (e.g. de saberes, de vivências, de materiais), mas também ao nível do desenvolvimento profissional do supervisor cooperante (e.g. desenvolvimento de competências reflexivas, pedagógicas e didácticas) ou dos benefícios decorrentes, para as escolas, da presença de núcleos de estágio.

A literatura aponta, igualmente, a presença de algumas dificuldades, que poderão ser o resultado de uma diversidade de factores de ordem interna e externa. Entre estes factores, salienta-se o papel dos contextos e das tarefas da prática supervisiva. Em relação aos contextos, Branquinho (2004) e Guimarães (2005) identificam vários problemas, de entre os quais os de nível organizacional (e.g. horários sobrepostos e excesso de serviço docente; parcas condições físicas; falta de tempo útil para reunir e realizar tarefas de reflexão e pesquisa), da cultura da escola (e.g. falta de apoio, reconhecimento, abertura e/ou receptividade da escola aos núcleos de estágio), e da articulação universidade-escola-supervisor (e.g. pouca cooperação entre os actores envolvidos; escassez de formação dirigida aos orientadores; número reduzido de visitas às escolas pelo supervisor da universidade; e algum distanciamento e/ou desconhecimento da realidade das escolas).

No que toca às tarefas supervisivas, os obstáculos prendem-se com a gestão da multiplicidade de responsabilidades e solicitações inerentes ao papel supervisivo e ao desgaste (físico e emocional) associado (Alarcão \& Tavares, 2003; Blumberg, 1980; Duquette, 1994; Esteves, 2006; Caires, Martins \& Moreira, 2008; Mestre, 2002). A avaliação formativa e a classificação dos estagiários surgem como as áreas de maior dificuldade, bem como a promoção da reflexividade entre os estagiários, avaliada como pouco desenvolvida (Branquinho, 2004; Casanova, 2001; Esteves, 2006; Leal, 2001). A estas problemáticas somam-se a gestão das relações e das 
dinâmicas do núcleo de estágio, entre as quais se destacam: a gestão dos conflitos e da competição entre estagiários; a inadequada gestão das tarefas no seio do grupo; a baixa motivação de alguns dos seus elementos; e o parco investimento na docência e nas tarefas de estágio. A irresponsabilidade e/ou imaturidade de alguns dos estagiários, um comportamento ético desadequado ou, ainda, as exigências inerentes ao adequado acompanhamento da prática pedagógica dos estagiários são igualmente evidenciadas na literatura (Duquette, 1994; Branquinho, 2004; Sinclair, et al., 2006). Segundo Pfeiffer e Dunlap (1982), as dificuldades de maior gravidade aparecem associadas às situações de rejeição, à atitude defensiva e/ou à conflituosidade na comunicação supervisor-estagiário.

Refira-se, entretanto, que as dificuldades anteriormente elencadas emergem, geralmente, em nível moderado, sendo superadas com relativa facilidade. Assim, na generalidade, 0 balanço que os supervisores cooperantes fazem do seu envolvimento nas funções supervisivas é globalmente positivo, sendo que as contrapartidas desta experiência são avaliadas como maiores e mais significativas (sob o ponto de vista profissional e pessoal) do que as dificuldades experienciadas (Branquinho, 2004; Esteves, 2006, 2007; Esteves et al., 2008). Todavia, e apesar da existência de estudos sobre esta problemática, persistem dificuldades na transferabilidade e generalização das evidências recolhidas e na definição de perfis adequados à função. Diferentes metodologias, amostras pouco representativas ou muito diferenciadas (e.g. tamanho, país, contexto formativo), bem como distintas abordagens do problema, estão na origem de algumas das limitações existentes.

\section{Método}

Tendo como foco as vivências e percepções dos supervisores cooperantes relativamente à sua experiência supervisiva, os investimentos dos autores ao longo dos últimos cinco anos têm tido como objectivo caracterizar alguns dos aspectos mais significativos desta experiência, explorando, especificamente, a óptica dos supervisores de escola que têm vindo a colaborar com a Universidade do Minho (Esteves, 2006, 2007; Esteves et al., 2008). No presente trabalho, dá-se a conhecer um dos investimentos mais recentes, que considera não apenas este contexto 
específico, mas também supervisores que colaboram com duas outras instituições de Ensino Superior: a Universidade do Porto e a Universidade de Trás-os-Montes e Alto Douro. Tomando por base supervisores cooperantes de três instituições distintas e de áreas científicas diversas (Educação Física, História, Biologia-Geologia, Inglês, Português, Alemão, Francês, Matemática e Física-Química), procurou-se averiguar (entre outros) em que medida aspectos como o tempo de serviço, os anos de experiência supervisiva, a sua área científica e a detenção (ou não) de uma formação especializada em supervisão influenciam o modo como vivenciam a sua experiência supervisiva. Em seguida apresentam-se alguns dos aspectos mais relevantes da metodologia adoptada.

\section{Instrumento}

O Inventário de Vivências e Percepções do Supervisor (IVPS Esteves, Caires \& Moreira, 2007) surge como o instrumento de base do estudo realizado, sendo composto por um total de 77 itens fechados, organizados em torno de uma escala likert de 5 pontos ( $1=$ totalmente em desacordo a 5 = totalmente de acordo). O IVPS avalia três grandes domínios da experiência dos supervisores cooperantes: o primeiro centrado nos benefícios ou contrapartidas percepcionados pelos supervisores como resultantes do seu envolvimento na supervisão de estágios; o segundo avaliando o impacto físico e emocional desta experiência; e o terceiro mais focado na avaliação de eventuais dificuldades decorrentes da adaptação às tarefas de supervisão.

Contendo um total de sete subescalas, o IVPS integra no seu primeiro domínio - Ganhos - cinco subescalas: (i) Ganhos gerais; (ii) Ganhos com os estagiários; (iii) Ganhos ao nível da escola; (iv) Ganhos decorrentes da colaboração com a universidade/Comissão de Estágio; e, finalmente, (v) Ganhos decorrentes da parceria com o supervisor da instituição de Ensino Superior.

A primeira subescala do domínio "Ganhos" é constituída por 13 itens e explora as percepções dos supervisores cooperantes relativamente aos ganhos gerais que a prática supervisiva lhes proporcionou, de entre os quais são exemplo o "Quebrar do isolamento profissional" ou o "Sentir-se útil na 
formação de novos professores". A segunda subescala procura, através de 9 itens, avaliar os ganhos decorrentes do trabalho desenvolvido com os estagiários, quer na esfera pessoal quer na esfera profissional (e.g. "Criar uma boa relação pessoal"; "Criar uma boa relação profissional"; "Trabalhar colaborativamente"). Na terceira subescala (7 itens), exploram-se as contrapartidas obtidas ao nível da escola (e.g. "Desenvolver actividades pedagógicas/formativas com outros Departamentos Curriculares" ou "Obter condições para desenvolver um trabalho eficiente [e.g. espaços e materiais didácticos]). Os 10 itens da quarta subescala avaliam os benefícios obtidos com a colaboração com a Comissão de Estágio (e.g. "Formação na área disciplinar"; "Formação em Metodologia de Ensino/Didáctica Específica"; "Formação em Supervisão Pedagógica"). Por fim, a quinta subescala (9 itens) examina as percepções dos supervisores cooperantes relativamente às maisvalias associadas à parceria estabelecida com o supervisor da instituição formadora (e.g. "Apoio científico-pedagógico"; "Cumplicidade").

A subescala que avalia o segundo domínio do IVPS - "Impacto pessoal" - é constituída por 10 itens, os quais procuram explorar as percepções dos supervisores relativamente às repercussões da experiência supervisiva no seu bem-estar físico e emocional (e.g. desgaste físico, níveis de stresse e tensão).

A sétima subescala, centrada no terceiro domínio do IVPS "Adaptação às tarefas de supervisão" (13 itens) - analisa algumas das dificuldades experienciadas no assumir das diferentes tarefas, funções e responsabilidades inerentes ao papel supervisivo (e.g. dificuldades na orientação das actividades lectivas dos estagiários: planificação, observação de aulas, etc.).

A par das sete subescalas anteriormente descritas, o IVPS contém, na parte final, um apartado ("Em jeito de balanço final..."), no qual é pedido ao supervisor que reflicta globalmente (e em retrospectiva) sobre a experiência supervisiva desenvolvida ao longo do ano lectivo em análise. Este apartado é constituído por 6 itens (de entre os quais um é aberto) e, nele, o supervisor procede à avaliação geral do seu desempenho e das mais-valias profissionais (para ele e para os estagiários) decorrentes da actividade realizada. É-lhe ainda solicitado que manifeste a sua intenção de continuar (ou não) a colaborar na supervisão de estágios pedagógicos no ano seguinte, justificando a sua opção. 


\section{Procedimentos}

O IVPS foi administrado no final do ano lectivo de 2007/8 (entre Maio e Junho). Previamente à sua aplicação, foram contactados os responsáveis pela coordenação dos estágios pedagógicos das Universidades do Minho, Porto e Trás-os-Montes e Alto Douro, aos quais foi solicitado o apoio na divulgação do estudo e na distribuição dos questionários junto de todos os supervisores cooperantes, de todas as disciplinas/áreas disciplinares, que cooperassem com estas três instituições de Ensino Superior. Juntamente com cada questionário, seguia uma carta, apresentando os objectivos do estudo, o pedido de colaboração e a garantia da confidencialidade e anonimato das respostas. Uma vez preenchidos, os questionários foram remetidos - via correio - à equipa de investigação.

\section{Participantes}

Os dados foram recolhidos junto de 141 supervisores cooperantes que, no ano lectivo de 2007/08, colaboraram com as Universidades do Minho, Porto e Trás-os-Montes e Alto Douro nas seguintes disciplinas: Educação Física, História, Biologia-Geologia, Inglês, Português, Alemão, Francês, Matemática, Física-Química - algumas delas organizadas em licenciaturas bidisciplinares. Os supervisores foram agrupados em três grandes áreas disciplinares. O quadro 1 dá a conhecer em maior detalhe as principais características deste grupo.

O grupo é maioritariamente constituído por elementos do sexo feminino (cerca de 77,5\%), com idades compreendidas entre os 25 e os 62 anos e uma média etária em torno dos 44 anos. Quanto ao tempo de serviço, a média ronda os 21 anos, oscilando entre os 10 e os 38 anos de experiência docente. Relativamente ao tempo de experiência supervisiva, a média ronda os 7 anos, existindo 9 professores $(6,8 \%)$ que pela primeira vez assumiram funções supervisivas. O supervisor mais experiente já assume funções supervisivas há 22 anos $(0,8 \%)$, sendo que a moda se situa nos 2 anos (21 professores - 15,9\%). 
Quadro 1 - Características sócio-demográficas do grupo de participantes

\begin{tabular}{|c|c|c|c|c|c|c|c|c|c|c|c|}
\hline \multirow[t]{2}{*}{$\begin{array}{l}\text { Área } \\
\text { Científica }\end{array}$} & \multicolumn{5}{|c|}{ Idade } & \multicolumn{3}{|c|}{ Anos de serviço } & \multicolumn{3}{|c|}{ Tempo de supervisão } \\
\hline & & $\mathrm{N}$ & Média & DP & $\begin{array}{l}\text { Min- } \\
\text { Max }\end{array}$ & Média & DP & $\begin{array}{l}\text { Min- } \\
\text { Max }\end{array}$ & Média & DP & $\begin{array}{l}\text { Min- } \\
\text { Max }\end{array}$ \\
\hline \multirow{2}{*}{$\begin{array}{l}\text { Educação } \\
\text { Física } \\
(n=31)\end{array}$} & Masc. & 11 & 45.4 & 5.85 & $36-53$ & 21.0 & 6.41 & $12-29$ & 5.6 & 2.62 & $2-10$ \\
\hline & Fem. & 20 & 44.3 & $6-07$ & $33-55$ & 20.8 & 6.11 & $10-33$ & 5.2 & 4.07 & $1-16$ \\
\hline \multirow{2}{*}{$\begin{array}{l}\text { Ciências } \\
\text { Exactas } \\
(n=26)\end{array}$} & Masc. & 10 & 42.9 & 7.03 & $36-59$ & 18.8 & 5.92 & $13-30$ & 7.0 & 2.73 & $3-10$ \\
\hline & Fem. & 16 & 43.1 & 5.96 & $32-56$ & 19.8 & 6.70 & $10-37$ & 7.5 & 5.51 & $2-18$ \\
\hline \multirow{2}{*}{$\begin{array}{l}\text { Humanidades } \\
(n=72)\end{array}$} & Masc. & 8 & 48.9 & 6.27 & $42-59$ & 25.6 & 7.35 & $18-38$ & 7.0 & 6.88 & $2-22$ \\
\hline & Fem. & 64 & 44.7 & 6.0 & $25-62$ & 22.0 & 5.07 & $13-37$ & 7.90 & 4.78 & $1-18$ \\
\hline Total $(\mathrm{N}=141)$ & & & 44.6 & 6.11 & $25-62$ & 21.5 & 6.00 & $10-38$ & 7.06 & 4.71 & $1-22$ \\
\hline
\end{tabular}

\section{Resultados}

Os principais resultados do presente estudo serão apresentados, numa primeira fase, considerando as respostas do grupo total nos três domínios do IVPS (quadro 2). Num segundo momento, analisam-se as diferenças existentes ao nível das vivências e percepções dos supervisores consoante as variáveis: i) "Área científica"; ii) "Tempo de supervisão"; iii) "Anos de serviço"; iv) "Formação pós-graduada em supervisão".

\section{As vivências e percepções dos supervisores cooperantes}

No quadro 2, apresentam-se a média, desvio-padrão e valores mínimo e máximo dos scores totais das respostas dos supervisores nos três domínios do IVPS: I) Ganhos (gerais; com os estagiários; com a escola; com a universidade; com o supervisor da universidade); II) Impacto pessoal; e III) Dificuldades na adaptação às tarefas de supervisão. Médias mais altas traduzem níveis de maior satisfação/conquista. Refira-se que, de modo a permitir a comparação entre os diferentes domínios/subescalas, as médias apresentadas consistem no somatório das respostas aos itens dividido pelo número total de itens do respectivo domínio/subescala. 
Quadro 2 - Vivências e percepções dos supervisores nos três domínios do IVPS

\begin{tabular}{lccc}
\hline Domínios/Subescalas & Média & D.P. & Min-Máx \\
\hline Ganhos gerais & 3.91 & .59 & $1.77-5$ \\
Ganhos com os estagiários & 4.18 & .56 & $1.89-5$ \\
Ganhos com a escola & 3.16 & .71 & $1-5$ \\
Ganhos com a universidade & 3.16 & .83 & $1-4.8$ \\
$\begin{array}{l}\text { Ganhos com o supervisor da } \\
\text { universidade }\end{array}$ & 4.08 & .75 & $2.1-5$ \\
$\begin{array}{l}\text { Impacto pessoal } \\
\text { Adaptação às tarefas de supervisão }\end{array}$ & 3.79 & .62 & $2.3-5$ \\
\hline
\end{tabular}

Os dados apresentados no quadro 2 revelam satisfação dos participantes relativamente aos benefícios decorrentes da experiência supervisiva, situando-se estes a um nível médio/médio-elevado. Com efeito, a média das respostas dos supervisores nestas dimensões gira em torno de 4, numa escala Likert de 5 pontos. Entre os benefícios destacam-se os ganhos reconhecidos ao nível do trabalho e relação desenvolvidos com os estagiários $(M=4.18)$, os ganhos decorrentes da parceria estabelecida com o supervisor da universidade $(\mathrm{M}=4.08)$, bem como os ganhos gerais percebidos como advindo desta experiência ( $M=3.91)$. A um nível intermédio, surgem, em exaequo, os ganhos decorrentes da colaboração com a universidade e as contrapartidas existentes ao nível de escola $(\mathrm{M}=3.16)$. No que concerne ao impacto pessoal resultante da assunção das múltiplas tarefas e responsabilidades inerentes às funções de supervisor, as respostas revelam um impacto mediano (M=3.09). Quanto à adaptação às tarefas de supervisão, a média das respostas dos participantes $(M=3.79)$ parece revelar a ausência de dificuldades expressivas no assumir destas tarefas, funções e responsabilidades. 


\section{Variáveis diferenciadoras da experiência supervisiva}

Numa tentativa de averiguar em que medida as variáveis i) "Área científica", ii) "Tempo de supervisão", iii) "Anos de serviço" e iv) "Formação pós-graduada em supervisão" diferenciam as vivências dos supervisores nas várias subescalas avaliadas pelo IVPS, foi realizado um conjunto de análises recorrendo-se à estatística inferencial.

\section{Influência dos anos de serviço docente e da prática supervisiva}

Procurando explorar a relação existente entre as experiências dos participantes - ao nível da docência e da supervisão - e as suas vivências e percepções relativamente aos benefícios, impacto pessoal e dificuldades na adaptação às tarefas de supervisão, procedeu-se a uma análise de correlação entre estas duas variáveis e as sete subescalas do IVPS. O mesmo tipo de análise foi feito com o intuito de averiguar a correlação existente entre as diferentes dimensões desta experiência. $\mathrm{O}$ quadro 3 apresenta os resultados obtidos.

Quadro 3 - Correlações entre as subescalas do IVPS, tempo de serviço e anos de supervisão

\begin{tabular}{|c|c|c|c|c|c|c|c|c|c|}
\hline & GG & GEst & GEsc & GU & GSup & IP & ATS & TS & AS \\
\hline Ganhos Gerais (GG) & -- & & & & & & & & \\
\hline $\begin{array}{l}\text { Ganhos Estagiários } \\
\text { (GEst) }\end{array}$ & $.68^{* *}$ & -- & & & & & & & \\
\hline Ganhos Escola (GEsc) & $.58^{* *}$ & $.60^{* *}$ & -- & & & & & & \\
\hline $\begin{array}{l}\text { Ganhos universidade } \\
\text { (GU) }\end{array}$ & $.27^{* *}$ & $.20^{*}$ & $.18^{*}$ & -.- & & & & & \\
\hline $\begin{array}{l}\text { Ganhos Supervisor } \\
\text { Universidade (GSup) }\end{array}$ & $.42^{* *}$ & $.41^{* *}$ & $.31^{* *}$ & $.39^{* *}$ & $\ldots$ & & & & \\
\hline Impacto Pessoal (IP) & $.37^{* *}$ & $.28^{* *}$ & $.31^{x *}$ & .16 & $.20^{*}$ & - & & & \\
\hline $\begin{array}{l}\text { Adaptação Tarefas } \\
\text { Supervisão (ATS) }\end{array}$ & -.017 & $.20^{*}$ & .15 & -.026 & -.056 & $-.38^{* *}$ & -.- & .027 & \\
\hline Tempo de Serviço (TS) & -.044 & -104 & -.028 & .025 & .023 & -.026 & .027 & --. & \\
\hline Anos Supervisão (AS) & -.001 & -.090 & -.082 & .032 & .012 & -.080 & .004 & $.38^{* *}$ & -. \\
\hline
\end{tabular}


Analisando os resultados do quadro 3 , constata-se que o leque das correlações entre as subescalas do IVPS relativas aos benefícios apresenta valores que variam entre .18 e .68, sendo que todas as intercorrelações entre as sete subescalas são moderadas ou elevadas, segundo os critérios propostos por Cohen (1988). A excepção surge nas intercorrelações que incluem a subescala "Ganhos Universidade", nas quais a magnitude das correlações é um pouco menor. Por seu turno, as percepções de impacto pessoal associam-se positivamente aos benefícios provenientes da experiência supervisiva (variando as intercorrelações entre .20 e .37), excepto na dimensão "Ganhos Universidade", cuja correlação não é significativa do ponto de vista estatístico. Quanto à dimensão "Adaptação às Tarefas de Supervisão", se, por um lado, se encontra uma correlação positiva com os "Ganhos Estagiários" ( $r=.20)$, por outro, constata-se uma correlação negativa com o "Impacto Pessoal" ( $r=-$.38). Finalmente, nenhuma das dimensões do IVPS evidencia correlações estatisticamente significativas nem com o tempo de serviço nem com os anos de supervisão.

\section{Influência da área científica dos supervisores de escola}

Por forma a explorar em que medida a área científica dos supervisores é diferenciadora das suas vivências e percepções, procedeu-se a uma análise multivariada, tomando as sete subescalas do IVPS e os três grupos científicos representados neste estudo: Educação Física, Humanidades e Ciências Exactas.

Testes multivariados revelaram a ausência de diferenças entre os supervisores de Educação Física, Letras e Humanidades e Ciências Exactas nas subescalas avaliadas [Pillai's Trace $=.16, F(7,118)=1.48, p=.12$ ]. Ao nível univariado, verifica-se que os supervisores de Educação Física, Letras e Humanidades e Ciências se distinguem apenas na subescala "Ganhos na escola" $[F(2,124)=3.25, p<.05]$. Testes Scheffe indicam que as diferenças significativas se registam entre os supervisores de Educação Física (EF) e os de Letras e Humanidades (LH), sendo que os maiores ganhos se verificam entre os de Educação Física (MEF= 3.40vs. $M L H=3.02$ ). 


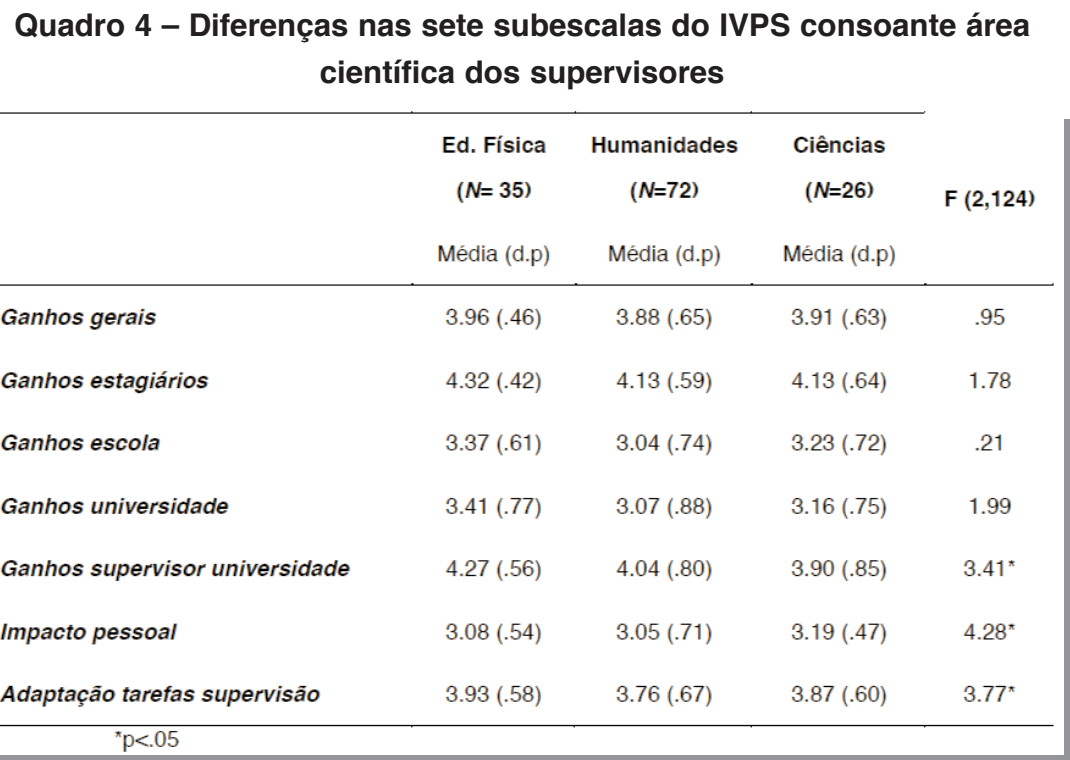

\section{Influência da detenção (ou não) de formação especializada em supervisão}

Do grupo total, $51 \%(n=72)$ dos supervisores declararam possuir formação pós-graduada. Numa tentativa de averiguar em que medida esta variável influencia as suas vivências e percepções em torno dos três domínios em análise, confrontaram-se as experiências dos supervisores cooperantes com formação especializada na área da supervisão com as dos supervisores com formação pós-graduada noutras áreas.

Um $t$-test entre os dois grupos revelou a presença de diferenças significativas apenas quanto às contrapartidas da colaboração com a universidade $[(\mathrm{t}=2.92 ; \mathrm{g} . \mathrm{I}=70 ; \mathrm{p}<0.01)]$, sendo estas percepcionadas como mais elevadas entre os supervisores com formação especializada na área. Nenhuma outra diferença foi encontrada ao nível das restantes subescalas. 
Quadro 5 - Diferenças nas médias no IVPS dos supervisores com pósgraduação em supervisão ou outras

\begin{tabular}{|c|c|c|c|}
\hline & $\begin{array}{l}\text { Pós-graduação } \\
\text { em Supervisão } \\
\qquad(N=28)\end{array}$ & $\begin{array}{l}\text { Outras } \\
(N=44)\end{array}$ & $\mathrm{t}(70)$ \\
\hline & Média (d.p.) & Média (d.p.) & \\
\hline Ganhos gerais & $3.97(.74)$ & $3.82(.54)$ & .96 \\
\hline Ganhos estagiários & $4.15(.69)$ & $4.16(.49)$ & -.06 \\
\hline Ganhos escola & $2.90(.89)$ & $3.17(.59)$ & -1.39 \\
\hline Ganhos universidade & $3.51(.80)$ & $2.95(.78)$ & $2.92^{\star \star}$ \\
\hline $\begin{array}{l}\text { Ganhos supervisor } \\
\text { universidade }\end{array}$ & $4.14(.79)$ & $3.93(.76)$ & 1.10 \\
\hline Impacto pessoal & $3.06(.69)$ & $3.00(.63)$ & .35 \\
\hline $\begin{array}{l}\text { Adaptação tarefas } \\
\text { supervisâo }\end{array}$ & $3.68(.67)$ & $3.87(.61)$ & -1.22 \\
\hline
\end{tabular}

\section{Discussão e conclusão}

O estudo apresentado visou explorar e apresentar alguns dos aspectos mais significativos da experiência supervisiva dos supervisores cooperantes a trabalhar na formação inicial de professores de três universidades portuguesas. Pretendeu averiguar o impacto desta experiência ao nível de três domínios centrais - benefícios, impacto pessoal e dificuldades na adaptação às tarefas de supervisão -, procurando, em cada um deles, responder à seguinte questão: Em que medida as variáveis "Área científica", "Anos de serviço", "Tempo de supervisão" e "Formação específica em supervisão" diferenciam as vivências e percepções dos participantes?

$\mathrm{Na}$ base desta questão surgiram quatro hipóteses centrais: i) as vivências e percepções dos supervisores cooperantes variam consoante a sua área científica; ii) existem diferenças entre os supervisores mais e menos 
experientes na forma como percepcionam os benefícios, impacto pessoal e dificuldades experienciadas na adaptação às tarefas de supervisão; iii) existem diferenças entre os supervisores na forma como percepcionam os benefícios, impacto pessoal e dificuldades experienciadas na adaptação às tarefas de supervisão consoante a longevidade da sua experiência docente; e iv) existem diferenças entre os supervisores pós-graduados na forma como percepcionam os benefícios, dificuldades e impacto pessoal da supervisão de estágios consoante detêm ou não formação especializada na área.

Relativamente à primeira hipótese, verificou-se que a área científica não é um factor diferenciador das vivências da experiência supervisiva, uma vez que não se identificaram diferenças significativas, à excepção dos ganhos percepcionados ao nível da escola. Nesta dimensão, os supervisores da Educação Física revelam-se mais satisfeitos do que os seus colegas das Humanidades. Refira-se que, muito embora não assumindo relevância estatística em termos das diferenças observadas nas restantes seis subescalas do IVPS, é entre os supervisores da Educação Física que as percepções, genericamente tomadas, são mais positivas. De salientar que este grupo de supervisores advém de apenas uma instituição, a Universidade do Porto, pelo que poderá espelhar uma avaliação mais concreta e focalizada do seu próprio projecto de formação inicial de professores e acompanhamento ao nível do estágio pedagógico, ao invés dos outros grupos que pertencem a várias universidades. Isto é, pretendemos realçar que os níveis de satisfação dos demais supervisores dizem respeito a uma maior diversidade de projectos formativos, não permitindo associá-la a uma instituição em particular.

No que diz respeito à segunda e terceira hipóteses, constatou-se que os anos de serviço e os anos de experiência supervisiva não diferenciam as vivências e percepções dos supervisores em nenhuma das subescalas avaliadas. Segundo Albuquerque et al. (2005), a experiência de ensino marca distintos posicionamentos face aos conceitos de ensinar e aprender, enquanto a experiência de supervisão traz estilos mais directivos. Por sua vez, Esteves et al. (2008), num estudo incidente nos supervisores da Universidade do Minho, verificaram que, quanto maior a experiência de ensino, menores as dificuldades de adaptação às tarefas supervisivas. Estes resultados pouco consonantes levam-nos a salientar o papel crucial dos contextos de formação, 
bem como a problematizar os indicadores de medida que são utilizados nos diferentes estudos e que, como afirmamos na introdução, não permitem comparações rigorosas entre eles.

Todavia, e neste estudo, as dificuldades experienciadas na adaptação às tarefas de supervisão estão negativamente correlacionadas com os ganhos gerais, com os decorrentes da colaboração com a universidade, com o supervisor da universidade, bem como com o impacto pessoal desta experiência. Ou seja, os supervisores que experienciaram menores dificuldades são aqueles que percepcionam menos ganhos em grande parte dos aspectos avaliados (gerais, pessoais, da universidade/CE e na interacção com o supervisor da universidade). Cremos que tais percepções se poderão dever a uma maior proximidade e cooperação, que se espera surgir quando há maiores dificuldades, entre os próprios supervisores e entre os supervisores e as instituições de Ensino Superior. Neste caso, a vivência da função assemelha-se a um percurso de aprendizagem, de gestão das dificuldades e dos obstáculos, que, no balanço final, surge como uma aprendizagem valiosa, sendo, neste percurso, o apoio da universidade genericamente de natureza formativa.

Contudo, e inversamente, no que respeita à subescala dos ganhos com os estagiários e com a escola, os supervisores que tiveram menos dificuldade na adaptação às tarefas de supervisão foram também aqueles que percepcionaram mais ganhos com os estagiários e com a escola. Aqui parece-nos que o suporte da escola e a boa relação pessoal e de trabalho estabelecida com os estagiários poderá atenuar eventuais dificuldades associadas às tarefas inerentes às funções supervisivas, salientando novamente o papel crucial desempenhado pelos contextos na facilitação ou inibição de processos favoráveis ao desenvolvimento profissional. Por outro lado, cremos ainda que a facilidade de adaptação às tarefas de supervisão cria um espaço/tempo maior para o desenvolvimento de outros contextos favoráveis; isto é, se o esforço e empenho não se situarem ao nível da adaptação às tarefas, por já estarem devidamente interiorizadas e executadas, resta mais tempo e disponibilidade para o desenvolvimento das relações com os estagiários e com a escola, destas resultando maiores ganhos/benefícios. 
Quanto à quarta hipótese do estudo, verificou-se que a detenção de uma pós-graduação em supervisão diferencia as percepções dos supervisores ao nível dos ganhos decorrentes da interacção com a universidade/CE. De facto, os supervisores com especialização em supervisão percepcionam mais ganhos na sua parceria com a universidade, possivelmente porque essa formação terá sido adquirida na universidade com a qual colaboram na supervisão dos estágios. No caso de algumas universidades (entre elas a Universidade do Minho), esta formação é incentivada (através de redução da propina e prioridade no acesso a estes cursos, por exemplo) e valorizada na selecção dos supervisores cooperantes. Adicionalmente, a formação especializada em supervisão promove saberes e competências específicos para o exercício da actividade, fomentando percepções mais positivas do supervisor relativamente à sua capacidade de confronto, gestão e resolução das exigências e desafios inerentes às suas práticas supervisivas. Por outro lado, maiores ganhos e satisfação percepcionados poderão decorrer também da maior motivação (logo à partida) destes supervisores para este tipo de tarefa, ao ponto de terem investido numa pós-graduação na área. A necessidade de possuir formação específica para o desempenho de funções especializadas não é apenas reconhecida formalmente (pela existência de um perfil de formação especializada em supervisão pedagógica e formação de formadores Despacho Conjunto n 198/99, de 15 de Fevereiro), mas também em estudos que a classificam como determinante para a melhoria do processo de formação inicial (Crasborn et al., 2008; Esteves, 2006; Parker-Katz \& Bay, 2008; Rodrigues \& Esteves, 2003).

Apresentados os resultados do estudo que tecemos, pretendemos ainda formular algumas reflexões acerca do contexto actual no qual se movem os supervisores pedagógicos. De facto, desde a aplicação da Portaria 1097/2005, os supervisores viram a sua condição de "formador" alterada, assumindo a supervisão pedagógica como mais uma tarefa acrescida às demais funções que assumem como docentes (às quais podem ainda somarse a de directores de turma, representantes disciplinares, ou outras). Tal, associado aos resultados positivos que o estudo apresenta quanto à avaliação da experiência, por parte dos supervisores, leva-nos a reflectir sobre as motivações que estes profissionais têm para o desempenho das 
funções supervisivas. Esteves (2006), relativamente a um contexto formativo anterior ao da referida portaria, apontou motivações maioritariamente do foro desenvolvimentista para a prática da supervisão, para além de outras que distinguiu como pessoais e profissionais. De entre aquelas, salientamos o "querer conhecer outras pessoas" e "manter o seu lugar de colocação na escola"; de entre as motivações profissionais, o "querer experienciar novos desafios" assumia a primeira posição. Face à alteração substancial das "condições de trabalho", seria interessante averiguar, na presente conjectura, quais as razões que movem os supervisores que actualmente colaboram com as universidades, bem como eventuais flutuações ocorridas no seu perfil (pessoal e sócio-demográfico).

\section{Referências}

Abrantes, M. M. (2005). O desenvolvimento da reflexividade no contexto do discurso supervisivo. Dissertação de Doutoramento em Supervisão. Aveiro: Universidade de Aveiro.

Alarcão, I. (Org.). (1996a). Formação reflexiva de professores: Estratégias de supervisão. Porto: Porto Editora.

Alarcão, I. (1996b). Reflexão crítica sobre o pensamento de D. Schön e os programas de formação de professores. In I. Alarcão (Org.), Formação reflexiva de professores: Estratégias de supervisão (pp. 9-39). Porto: Porto Editora.

Alarcão, I., \& Tavares, J. (2003). Supervisão da prática pedagógica: Uma perspectiva de desenvolvimento e de aprendizagem. Coimbra: Almedina.

Albuquerque, A., Graça, A., \& Januário, C. (2005). A supervisão pedagógica em Educação Física. Lisboa: Livros Horizonte.

Barbosa, I. (2003). O discurso da supervisão na formação reflexiva de professores estagiários. Tese de Mestrado em Educação. Braga: Universidade do Minho.

Beck, C., \& Kosnik, C. (2000). Associate teachers in pre-service education: Clarifying and enhancing their role. Journal of Education for Teaching, 26(3), 207-224.

Bennett, T. (1997). Clinical supervision marriage: A matrimonial metaphor for understanding the supervisor-teacher relationship. Disponivel em http://eric.ed.gov/ERICWebPortal/custom/portlets/recordDetails/ detailmini.jsp?_nfpb=true\&_\&ERICExtSearch_SearchValue_0=ED408246\&ERI CExtSearch_Sear chType_0=no\&accno=ED408246 (acesso em Setembro de 2008).

Blumberg, A. (1980). Supervisors and teachers: A private cold war. Berkeley, CA: McCutchan Publishing Corporation. 
Branquinho, E. (2004). Percepções dos orientadores de escola sobre a supervisão e a prática supervisiva. Tese de Mestrado em Supervisão. Aveiro: Universidade de Aveiro.

Caires, S. (2003). Vivências e percepções do estágio pedagógico: A perspectiva dos estagiários da Universidade do Minho. Dissertação de Doutoramento em Psicologia. Braga: Universidade do Minho.

Casanova, M. P. (2001). Supervisão pedagógica: Função do orientador de estágio na escola. Disponível em http://www.educ.fc.ul.pt/recentes/mpfip/pdfs/ mprazerescasanova.pdf (acesso em Junho de 2010).

Cohen, J. (1988). Statistical power analysis for the behavioural sciences. Hillsdale, NJ: Erlbaum.

Crasborn, F., Hennisen, P., Brouwer, N., Korthagen, F., \& Bergen, T. (2008). Promoting versatility in mentor teachers' use of supervisory skill. Teaching and Teacher Education, 24, 499-514.

Duquette, C. (1994). The role of the cooperating teacher in a school-based teacher education program: Benefits and concerns. Teaching and Teacher Education, 10(3), 345-353.

Esteves, C. H. (2006). Vivências e percepções do estágio pedagógico pelo supervisor da escola: Um estudo na Universidade do Minho. Tese de Mestrado em Educação. Braga: Universidade do Minho.

Esteves, C. H. (2007). Viver a supervisão - Um estudo na Universidade do Minho. In A. Barca, M. Peralbo, B. D. Silva \& L. Almeida (Eds.), Libro de Actas do IX Congresso Internacional Galego-Portugués de Psicopedagoxía. A Coruña: Universidade da Coruña, CD-ROM.

Esteves, C. H., Caires, S., \& Moreira, M. A. (2007). Supervisão: Motivações e expectativas dos supervisores. In A. Barca, M. Peralbo, B. D. Silva \& L. Almeida (Eds.), Libro de actas do IX Congresso Internacional Galego-Portugués de Psicopedagoxía. A Coruña: Universidade da Coruña, CD-ROM.

Esteves, C. H., Caires, S., Martins, C., \& Moreira, M. A. (2008). Vivências da supervisão de estágios pedagógicos dos supervisores de escola: Factores diferenciadores. Revista Galego-Portuguesa de Psicopedagoxia e Educación, 16(1), 153-168.

Estrela, M. T., Esteves, M., \& Rodrigues, A. (2002). Síntese da investigação sobre formação inicial de professores em Portugal (1990-2000). Porto: Porto Editora.

Feiman-Nemser, S. (2001). Helping novices learn to teach: Lessons from an exemplary support teacher. Journal of Teacher Education, 52(1), 17-30.

Flores, M. A. (2006). Being a novice teacher in two different settings: Struggles, continuities and discontinuities. Teachers College Record, 108, 2021-2052.

Galvão, C. (1996). Estágio pedagógico: Cooperação na formação. Revista de Educação, VI, 71-87.

Guimarães, E. (2005). Colaboração supervisiva no contexto do estágio pedagógico. Tese de Mestrado em Supervisão. Aveiro: Universidade de Aveiro.

King, S. (2004). Emerging models of teacher training in England. International Research in Geographical and Environmental Education, 1(2), 197-204. 
Leal, S. (2001). Um contributo para a caracterização das práticas supervisivas ao nível da formação inicial de professores na Região dos Açores. Disponível em http://www.educ.fc.ul.pt/recentes/mpfip/pdfs/ susanaleal.pdf (acesso em Junho de 2010).

Mestre, M. J. (2002). Avaliação num contexto de supervisão. Lisboa: Instituto de Inovação Educacional.

Moreira, M. A. (2005). A investigação-acção na formação em supervisão no ensino do Inglês: Processos de (co-)construção do conhecimento profissional. Braga: Centro de Investigação em Educação da Universidade do Minho.

Pacheco, J. A. (1995). Formação de professores: Teoria e praxis. Braga: Universidade do Minho.

Pajak, E. (1990). Identification of dimensions of supervisory practice in education: Reviewing the literature. Disponível em http://www.eric.ed.gov/ERICDocs/data/ ericdocs2sql/ content_storage_01/0000019b/80/20/74/db.pdf (acesso em Setembro de 2008).

Parker-Katz, M., \& Bay, M. (2008). Conceptualizing mentor knowledge: Learning from the insiders. Teaching and Teacher Education, 14, 1259-1269.

Pfeiffer, I., \& Dunlap, J. (1982). Supervision of teachers: A guide to improve instruction. Phoenix: Oryx Press.

Ribeiro, D. (1996). Modelos e estilos de supervisão facilitadores dos processos de autonomia. Tese de Mestrado em Supervisão. Aveiro: Universidade de Aveiro.

Ribeiro, D. (2006). A investigação-acção colaborativa na formação de supervisores: Um estudo de caso na Educação de Infância. Dissertação de Doutoramento em Estudos da Criança. Braga: Universidade do Minho.

Riordan, G. (1995). Teachers' perceptions of collaboration and clinical supervision. Disponivel em http://www.eric.ed.gov/ERICDocs/data/ericdocs2sql/ content_storage_01/0000019b/80/14/1a/1e.pdf (acesso em Setembro de 2008).

Rodrigues, A., \& Esteves, M. (2003). Tornar-se professor. Investigar em Educação, 2, $15-68$

Sá-Chaves, I. (2002). Formação de professores: Modelos de referência na Universidade de Aveiro. Revista de Educação, X(1), 150-153.

Schmidt, M. (2008). Mentoring and being mentored: The story of a novice music teacher's success. Teaching and Teacher Education, 24, 635-648.

Sinclair, C., Dowson, M., \& Thistleton-Martin, J. (2006). Motivations and profiles of cooperating teachers: Who volunteers and why? Teaching and Teacher Education, 22(3), 263-279.

Vieira, F. (1993). Supervisão: Uma prática reflexiva de formação de professores. Rio Tinto: Asa.

Vieira, F., Moreira, M. A., Barbosa, I., Paiva, M., \& Fernandes, I. S. (2006). No caleidoscópio da supervisão: Imagens da formação e da pedagogia. Mangualde: Edições Pedago. 


\section{EXPERIENCES AND PERCEPTIONS OF PARTICIPANTS IN INITIAL TEACHER EDUCATION: THE COOPERATING TEACHER}

\section{Abstract}

This paper studies the experiences of cooperating teachers regarding the supervision of student teachers in their practicum year. A study was conducted with 155 cooperating teachers that have cooperated with four public universities in the school year of 2007/8. Their experience was studied with the instrument Inventory of Experiences and Perceptions of the Cooperating Teacher (IVPS in portuguese - Esteves, Caires \& Moreira, 2008). This instrument has 77 items and assesses three central domains of the cooperating teachers' experiences: i) benefits, ii) personal impact, and iii) difficulties in the adaptation to the supervisory tasks. It is our aim to investigate the extent in which the variables 'Scientific domain', 'Teaching years', 'Supervisory experience', and 'Specialized training in supervision' differentiate the experiences and perceptions of the participants. Data collected point out the lack of impact of the first three variables and the influence of the last in the experiences and perceptions of the cooperating teachers.

Keywords

Experiences; Perceptions; Cooperating teacher

\section{EXPÉRIENCES VÉCUES ET PERCEPTIONS DES AGENTS DE LA FORMATION INITIALE DE PROFESSEURS: LE TUTEUR DE STAGE}

\section{Résumé}

Cet article se centre sur les expériences personnelles vécues par les tuteurs de stage, au niveau du processus d'accompagnement des stages pédagogiques. Celui-ci présente une étude qui a impliqué 155 tuteurs qui ont collaboré, au long de l'année scolaire 2007/08, avec quatre universités 
publiques portugaises et dont les expériences ont été évaluées par l'Inventaire d'Expériences Personnelles et Perceptions du Tuteur (IVPS en portugais Esteves, Caires \& Moreira, 2008). Cet inventaire, ayant un total de 77 items, évalue trois importants domaines des expériences des tuteurs de stage, dans les écoles: i) les bénéfices, ii) l'impact personnel et iii) les difficultés d'adaptation aux tâches liées à la supervision. Comme objectif, nous voulons vérifier si les variables «Domaine scientifique», «Années de travail enseignant», «Années d'expérience comme tuteur» et «Formation spécialisée en supervision» influencent les expériences personnelles et les perceptions des tuteurs participants. Les données recueillies indiquent que les trois premières variables ne sont pas influentes alors que la dernière l'est, effectivement.

Mots-clé

Expériences vécues; Perceptions; Tuteurs; Stage

Recebido em Novembro, 2010 Aceite para publicação em Julho, 2011 do Minho, Instituto de Educação, Campus de Gualtar, 4710-057 Braga, Portugal. Telef.: +351 604 255. E.mail: caires@ie.uminho.pt 